Research Article

\title{
Effect of Different Coloring Procedures on the Aging Behavior of Dental Monolithic Zirconia
}

\author{
Check Agingu $\mathbb{D}^{1},{ }^{1}$ Neng-wu Jiang, ${ }^{1}$ Hui Cheng $\mathbb{D}^{1,},{ }^{1,2}$ and Hao $\mathrm{Yu} \mathbb{D}^{1,2,3}$ \\ ${ }^{1}$ Department of Prosthodontics, School and Hospital of Stomatology, Fujian Medical University, Fuzhou, China \\ ${ }^{2}$ Key Laboratory of Stomatology, Fujian Province University, Fuzhou, China \\ ${ }^{3}$ Department of Applied Prosthodontics, Graduate School of Biomedical Sciences, Nagasaki University, Nagasaki, Japan
}

Correspondence should be addressed to Hao Yu; haoyu-cn@hotmail.com

Received 31 January 2018; Revised 25 April 2018; Accepted 10 May 2018; Published 11 July 2018

Academic Editor: Davidson Sajan

Copyright (c) 2018 Check Agingu et al. This is an open access article distributed under the Creative Commons Attribution License, which permits unrestricted use, distribution, and reproduction in any medium, provided the original work is properly cited.

\begin{abstract}
Objective. This study aimed to investigate the effect of different coloring procedures on the aging behavior of dental monolithic zirconia. Methods. Two types of translucent zirconia (SuperfectZir HTS, Aidite; Katana HT, Kuraray) were tested. Bar-shaped specimens with dimensions of $22 \times 4 \times 2 \mathrm{~mm}$ were prepared from uncolored and precolored blocks. Before being sintered, specimens made from uncolored blocks were colored by dipping them into a coloring liquid, whereas the precolored specimens were not treated. The specimens were then divided into 4 subgroups $(n=13)$ according to the aging conditions (no aging, $134^{\circ} \mathrm{C} / 0.2 \mathrm{MPa}$ for $5 \mathrm{~h}, 134^{\circ} \mathrm{C} / 0.2 \mathrm{MPa}$ for $10 \mathrm{~h}$, and $134^{\circ} \mathrm{C} / 0.2 \mathrm{MPa}$ for $20 \mathrm{~h}$ ). The flexural strength of the specimens was tested with the 4-point flexure. The crystalline phase composition of the specimens was analyzed by XRD. The subsurface microstructure of the fractured specimens was examined by using a SEM. The data were statistically analyzed using 3-way ANOVA and Tukey's test $(\alpha=0.05)$. Results. Significant differences were found in the flexural strength between the two zirconia materials tested $(P<0.001)$. Aging and coloring procedures showed no significant effect on the flexural strength of the zirconia. Aging and coloring procedures significantly affected the $t \rightarrow m$ transformation of the zirconia. The monoclinic phase increased with the aging time. After aging, the precolored specimens showed a significantly higher $\mathrm{t} \rightarrow \mathrm{m}$ transformation than the specimens that were dipped in the coloring liquids. After aging for $20 \mathrm{~h}$, the depth of the transformed zone with an irregular surface was approximately $6 \mu \mathrm{m}$ for SuperfectZir HTS, whereas no detectable transformation zone was observed for Katana HT. Conclusion. Aging and coloring procedures had no significant effects on the flexural strength of the zirconia tested. The coloring procedure had a significant effect on the phase transformation of the zirconia subjected to hydrothermal aging.
\end{abstract}

\section{Introduction}

In recent years, zirconia has been widely used in dentistry due to its excellent mechanical and aesthetics properties and its biocompatibility [1]. Zirconia exists in 3 crystallographic forms: a monoclinic phase $(\mathrm{m})$, which is stable between room temperature and $1170^{\circ} \mathrm{C}$, a tetragonal phase $(\mathrm{t})$, which is stable between $1170^{\circ} \mathrm{C}$ and $2370^{\circ} \mathrm{C}$, and a cubic phase (c), which is stable over $2370^{\circ} \mathrm{C}$ [2]. The addition of stabilizers such as $\mathrm{MgO}$ and $\mathrm{Y}_{2} \mathrm{O}_{3}$ can stabilize the zirconia in the tetragonal phase at room temperature [3]. For biomedical applications, zirconia is usually stabilized with
3 mol\% ytrria (yttria-stabilized tetragonal zirconia polycrystal, Y-TZP) [4]. When the Y-TZP is exposed to stress, its metastable structure undergoes a $\mathrm{t} \rightarrow \mathrm{m}$ phase transformation, resulting in a volumetric expansion that can stop crack propagation [5]. However, the $t \rightarrow m$ transformation of zirconia can occur without stress under moist conditions, which is referred to as low temperature degradation (LTD) or aging [6]. After the transformation, intergranular microcracking appears, which degenerates the mechanical properties of the Y-TZP $[7,8]$. Evidence of LTD has been observed in zirconia hip implants [9]. To date, the mechanism to explain LTD is still unclear. 
TABLE 1: Characteristics of the materials used in the present study.

\begin{tabular}{|c|c|c|c|c|c|c|}
\hline \multirow{2}{*}{$\begin{array}{l}\text { Zirconia } \\
\text { materials }\end{array}$} & \multirow{2}{*}{ Manufacturers } & \multirow{2}{*}{ Chemical components (wt.\%) } & \multirow{2}{*}{$\begin{array}{l}\text { Grain size } \\
\quad(\mu \mathrm{m})\end{array}$} & \multirow{2}{*}{$\begin{array}{l}\text { Density } \\
\left(\mathrm{g} / \mathrm{cm}^{3}\right)\end{array}$} & \multicolumn{2}{|c|}{ Sintering conditions } \\
\hline & & & & & Temperature $\left({ }^{\circ} \mathrm{C}\right)$ & Dwelling time $(\mathrm{h})$ \\
\hline SuperfectZir HTS & Aidite, China & $\mathrm{ZrO}_{2}+\mathrm{HfO}_{2}: 92-96 \%, \mathrm{Y}_{2} \mathrm{O}_{3}: 5-6 \%$ & 0.54 & 6.09 & 1530 & 2 \\
\hline Katana HT & Kuraray, Japan & $\mathrm{ZrO}_{2}+\mathrm{HfO}_{2}: 90-95 \%, \mathrm{Y}_{2} \mathrm{O}_{3}: 5-8 \%$ & n.a. & 5.90 & 1500 & 2 \\
\hline
\end{tabular}

${ }^{*}$ Information provided by the manufacturers.

Although evidence of LTD is limited in Y-TZP in dental applications, the $\mathrm{t} \rightarrow \mathrm{m}$ transformation was observed after accelerated aging. Using X-ray diffraction (XRD), MunozTabares et al. [11] measured the monoclinic phase fraction $\left(V_{\mathrm{m}}\right)$ of zirconia samples aged in an autoclave and revealed that $V_{\mathrm{m}}$ increased from $25 \%$ to $45 \%$ after $86 \mathrm{~h}$ of aging. Wulfman et al. [11] reported that the surface $\mathrm{t} \rightarrow \mathrm{m}$ transformation increased with aging time. The greatest $V_{\mathrm{m}}(70 \%)$ was found after $25 \mathrm{~h}$ and $90 \mathrm{~h}$ of aging. In another laboratory study, up to $40 \% V_{\mathrm{m}}$ was observed on a Y-TZP surface after $20 \mathrm{~h}$ of hydrothermal aging. However, this extent of phase transformation failed to significantly affect the biaxial flexural strength of the Y-TZP tested [12]. Moreover, Flinn et al. [13] reported a significant correlation between the decrease in the flexural strength and the increase in $V_{\mathrm{m}}$ for certain types of Y-TZP (Prettau and BruxZir). The literature indicates that the resistance to LTD of Y-TZP is materialdependent. Even small deviations in the composition, grain size, and processing methods lead to huge differences in LTD behaviors of Y-TZP $[14,15]$. Additionally, surface treatment of Y-TZP, such as grinding, can induce superficial modifications and the $\mathrm{t} \rightarrow \mathrm{m}$ transformation $[16,17]$.

The basic color of Y-TZP ranges from white to ivory. To achieve a more natural appearance, 2 coloring procedures are available for dental prosthesis fabrication: (1) adding coloring pigments such as metal oxides to the raw zirconia powder at the production stage to obtain precolored zirconia blocks and (2) dipping the presintered, uncolored zirconia block in coloring liquids containing various metal ions, such as iron $(\mathrm{Fe})$, erbium (Er), and cerium (Ce) [18]. However, the various ions in the coloring liquid may act as impurities in the Y-TZP and further change its aging behavior [19]. Ban et al. [19] reported a reduction in the fracture toughness and flexural strength of the Y-TZP colored by dipping in a coloring liquid. However, the effect of coloring was found to be dependent on the liquid. Wille et al. [12] reported that different concentrations of coloring pigments led to different LTD behavior of the zirconia and up to $40 \%$ of the monoclinic phase was detected after aging. Shah et al. [20] concluded that there was no detectable amount of the monoclinic phase in Y-TZP colored by coloring liquids or in uncolored controls. To the best of the authors' knowledge, very limited information is available regarding the influences of different coloring procedures on the aging behavior of Y-TZP.

The objective of the present study was to evaluate the effects of different coloring approaches on the aging behavior of Y-TZP. The null hypothesis was that the flexural strength and the phase transformation of two Y-TZP materials colored by different procedures would not be affected by hydrothermal aging.

\section{Materials and Methods}

2.1. Specimen Preparation. Two types of translucent Y-TZP (Katana HT, Kuraray, Japan; SuperfectZir HTS, Aidite, China) were selected for this study. A summary of the characteristics of the investigated Y-TZP is listed in Table 1. Bar-shaped specimens were milled using computer-aided design/computeraided manufacturing (CAD/CAM) technology (Zenotec, Wieland, Germany) with compensation for the shrinkage induced by sintering. A $45^{\circ}$ chamfer was fashioned on the edge of each specimen. For each material tested, 52 precolored (shade A2) and 52 noncolored specimens were prepared and smoothed with 600-grit and 1200-grit carborundum discs (Buehler, Lake Bluff, IL, USA) under water cooling. The specimens were cleaned in distilled water using an ultrasonic bath (KQ-250DB, Kunshan Ultrasonic Instruments, China) for $15 \mathrm{~min}$. The noncolored specimens were dipped with plastic tweezers into the coloring liquid (Zirconia coloring liquid A2, Aidite, China) for $2 \mathrm{~min}$ at room temperature following the manufacturer's instructions, whereas the precolored specimens were not treated. The coloring liquid contained $\mathrm{Er}\left(\mathrm{NO}_{3}\right)_{3}$ at 0.30 mole/liter solvent, $\operatorname{Pr}\left(\mathrm{NO}_{3}\right)_{3}$ at 0.01 mole/liter solvent, Ce $\left(\mathrm{NO}_{3}\right)_{3}$ at 0.10 mole/liter solvent, and $\mathrm{Nd}\left(\mathrm{NO}_{3}\right)_{3}$ at 0.10 mole/liter solvent. Once removed, the excess coloring liquid on the noncolored specimen was gently absorbed with blotting paper. The precolored specimens were assigned to the PRE group. The specimens colored by dipping into the coloring liquids were assigned to the DIP group. After being dried for $2 \mathrm{~h}$ at $37^{\circ} \mathrm{C}$, the specimens in the PRE and DIP groups were sintered according to the manufacturers' instructions. The heating and cooling rates were $10^{\circ} \mathrm{C} / \mathrm{min}$, and the specimens were maintained at maximum temperatures for $2 \mathrm{~h}$ (Table 1 ). After being sintered, the specimens; final dimension $(22 \mathrm{~mm}$ in length, $4 \mathrm{~mm}$ in width, and $2 \mathrm{~mm}$ in thickness) was achieved according to ISO 6872: 2015 [21]. To simulate the clinical situation, the specimens were further polished with a fine-grit laboratory zirconia polisher (Circopol Lab, DFS Diamon, Germany) and diamond paste.

The specimens were ultrasonically cleaned in distilled water for 2 min before use. The specimens in the PRE and DIP groups were randomly divided into 4 subgroups based on the aging treatment $(n=13)$.

2.2. Aging Treatment. The samples were aged in an autoclave (HE-50, Hirayama, Japan) at $134^{\circ} \mathrm{C}$ in a water vapor atmosphere at $0.2 \mathrm{MPa}$. The aging conditions were as follows: no aging (control), $134^{\circ} \mathrm{C} / 0.2 \mathrm{MPa}$ for $5 \mathrm{~h}, 134^{\circ} \mathrm{C} / 0.2 \mathrm{MPa}$ for $10 \mathrm{~h}$, and $134^{\circ} \mathrm{C} / 0.2 \mathrm{MPa}$ for $20 \mathrm{~h}$. The sample labels for each material are described in Table 2. 
TABLE 2: Sample labels for the materials tested in this study.

\begin{tabular}{lcc}
\hline Coloring procedure & Aging period & Code \\
\hline & $0 \mathrm{~h}$ & PRE-C \\
Precolored & $5 \mathrm{~h}$ & PRE-5 \\
& $10 \mathrm{~h}$ & PRE-10 \\
& $20 \mathrm{~h}$ & PRE-20 \\
\hline & $0 \mathrm{~h}$ & DIP-C \\
Colored by dipping in coloring liquids & $5 \mathrm{~h}$ & DIP-5 \\
& $10 \mathrm{~h}$ & DIP-10 \\
& $20 \mathrm{~h}$ & DIP-20 \\
\hline
\end{tabular}

2.3. Flexural Strength Test. Four-point flexure was performed using a universal testing machine (AGS-10kNG, Shimadzu, Kyoto, Japan) at a crosshead speed of $1 \mathrm{~mm} /$ min until failure $(n=10)$. The specimens were tested dry at room temperature, and the dimensions were measured with a digital micrometer (Mitutoyo, Tokyo, Japan). Flexural strength values were calculated using the following equation [21]:

$$
\sigma=\frac{3 P l}{4 w b^{2}}
$$

where $P$ is the fracture load (in $N$ ), $l$ is the test span (distance between the exterior supports in $\mathrm{mm}$ ), $w$ is the width of the specimen (in $\mathrm{mm}$ ), and $b$ is the thickness of the specimen (in $\mathrm{mm})$.

2.4. XRD Measurement. The crystalline phases of the specimens from each group $(n=3)$ were analyzed using XRD (Empyrean, PANalytical, the Netherlands). The patterns were recorded at $40 \mathrm{kV}$ (generator voltage) and $40 \mathrm{~mA}$ (tube current) with $\mathrm{Cu} K \alpha$ radiation. The scan range for $2 \theta$ was between $26^{\circ}$ and $36^{\circ}$, with a step size of $0.013^{\circ}$ and a scan time of $18.87 \mathrm{~s} / \mathrm{step}$. The obtained XRD patterns were analyzed using analysis software and data from the International Centre for Diffraction Data (ICDD).

The monoclinic phase fraction $\left(X_{\mathrm{m}}\right)$ was calculated according to the method described by Garvie and Nicholson [22]:

$$
X_{\mathrm{m}}=\frac{I_{\mathrm{m}}(\overline{1} 11)+I_{\mathrm{m}}(111)}{I_{\mathrm{m}}(\overline{1} 11)+I_{\mathrm{m}}(111)+I_{\mathrm{t}}(101)},
$$

where $I_{\mathrm{m}}(\overline{1} 11)$ and $I_{\mathrm{m}}(111)$ are the monoclinic peak intensities at $2 \theta=28.175^{\circ}$ and $31.468^{\circ}$, respectively, and $I_{\mathrm{t}}(101)$ is the tetragonal peak intensity at $2 \theta=29.807^{\circ}$ [23].

The monoclinic volume fraction $\left(V_{\mathrm{m}}\right)$ was then calculated according to the method described by Toraya et al. [24]:

$$
V_{\mathrm{m}}=\frac{1.311 X_{\mathrm{m}}}{1+0.311 X_{\mathrm{m}}} \text {. }
$$

2.5. SEM Observation. The cross-sectional topography patterns were examined using a scanning electron microscope (Quanta 250, FEI, USA). For each type of zirconia, 2 samples from each group were randomly selected after aging for SEM examination. The specimens were fractured during the 4-point flexure, and the cross sections were mounted on aluminum stubs and sputter-coated with gold before being examined at an acceleration voltage of $20 \mathrm{kV}$.

2.6. Statistical Analysis. The data were analyzed using the SPSS statistical software package (SPSS 13.0 for Windows, SPSS, Chicago, IL, USA). The statistical analysis was performed using three-way analysis of variance (ANOVA) and Tukey's HSD test to determine significant differences between the phase transformations and flexural strength of the materials tested $(P<0.05)$.

\section{Results}

The Shapiro-Wilk test confirmed the normal distribution of the data. The means and standard deviations of the flexural strength are shown in Table 3. Katana HT showed significantly greater flexural strength than SuperfectZir HTS $(P<0.001)$. Aging and coloring procedures had no significant effects on the flexural strength of the materials tested ( $P=0.474$ and $P=0.414$, resp.). The means and standard deviations of $V_{\mathrm{m}}$ are listed in Table 4 . After aging, $V_{\mathrm{m}}$ ranged from $7.26 \%$ (group DIP-5, Katana HT) to $37.58 \%$ (group PRE-20, SuperfectZir HTS). Katana HT showed a lower mean $V_{\mathrm{m}}$ after aging and was much more resistant to the phase transformation than SuperfectZir HTS. Aging and coloring procedures had significant effects on the phase transformation of the materials tested (all $P<0.001$ ). The phase transformation was observed with increased aging time. Specimens in the PRE group were found to be more sensitive to aging (greater $t \rightarrow m$ transformation) than those in the DIP group.

The monoclinic peak intensity increased and the tetragonal peak intensity decreased with increased aging time (Figure 1). SEM images of representative fracture surfaces of the specimens aged for $20 \mathrm{~h}$ are shown in Figure 2. After aging for $20 \mathrm{~h}$, the thickness of the region with the monoclinic phase (the depth of transformation) was found to be approximately $6 \mu \mathrm{m}$ for SuperfectZir HTS, whereas no detectable transformation zone was observed for Katana HT.

\section{Discussion}

Based on the current findings, the null hypothesis that the aging and coloring procedures would not affect the amount of $\mathrm{t} \rightarrow \mathrm{m}$ transformation of monolithic Y-TZP was rejected. The null hypothesis that the aging and coloring procedures would not affect the flexural strength of monolithic Y-TZP was accepted.

Various studies have investigated the effects of accelerated aging on Y-TZP. However, publications discussing whether the coloring procedures affect the aging behavior of Y-TZP are lacking. This laboratory study was therefore designed to evaluate the aging behavior of Y-TZP colored with different coloring approaches using a hydrothermal aging process. Published studies have a wide variability in aging protocols, and up to $200 \mathrm{~h}$ hydrothermal aging has been adopted in the literature [13]. Chevalier et al. $[14,25]$ proposed that aging in the autoclave at $134^{\circ} \mathrm{C}$ and $0.2 \mathrm{MPa}$ for $5 \mathrm{~h}$ is equivalent to $15-20$ years of in vivo use 
TABLE 3: Means and standard deviations of the flexural strength (MPa) for each group.

\begin{tabular}{|c|c|c|c|c|c|c|c|c|}
\hline Materials & PRE-C & PRE-5 & PRE-10 & PRE-20 & DIP-C & DIP-5 & DIP-10 & DIP-20 \\
\hline $\begin{array}{l}\text { SuperfectZir } \\
\text { HTS }\end{array}$ & $\begin{array}{c}750.77 \\
(51.52)^{\mathrm{a}, \mathrm{A}}\end{array}$ & $\begin{array}{c}778.80 \\
(50.82)^{\mathrm{a}, \mathrm{A}}\end{array}$ & $\begin{array}{c}770.04 \\
(53.47)^{\mathrm{a}, \mathrm{A}}\end{array}$ & $\begin{array}{c}784.36 \\
(58.75)^{\mathrm{a}, \mathrm{A}}\end{array}$ & $\begin{array}{c}804.35 \\
(73.39)^{\mathrm{a}, \mathrm{A}}\end{array}$ & $\begin{array}{c}819.81 \\
(66.57)^{\mathrm{a}, \mathrm{A}}\end{array}$ & $\begin{array}{c}806.76 \\
(69.30)^{\mathrm{a}, \mathrm{A}}\end{array}$ & $\begin{array}{c}775.32 \\
(46.43)^{\mathrm{a}, \mathrm{A}}\end{array}$ \\
\hline Katana HT & $\begin{array}{c}951.73 \\
(71.25)^{\mathrm{b}, \mathrm{A}}\end{array}$ & $\begin{array}{c}1009.72 \\
(84.09)^{\mathrm{b}, \mathrm{A}}\end{array}$ & $\begin{array}{c}1029.10 \\
(79.44)^{\mathrm{b}, \mathrm{A}}\end{array}$ & $\begin{array}{c}1042.29 \\
(69.68)^{\mathrm{b}, \mathrm{A}}\end{array}$ & $\begin{array}{c}973.24 \\
(63.17)^{\mathrm{b}, \mathrm{A}}\end{array}$ & $\begin{array}{c}1019.56 \\
(88.64)^{\mathrm{b}, \mathrm{A}}\end{array}$ & $\begin{array}{c}1015.43 \\
(73.19)^{\mathrm{b}, \mathrm{A}}\end{array}$ & $\begin{array}{c}1050.08 \\
(82.06)^{\mathrm{b}, \mathrm{A}}\end{array}$ \\
\hline
\end{tabular}

*Values marked with the same lowercase letter were not significantly different within a column $(P>0.05)$. Values marked with the same uppercase letter were not significantly different in each group $(P>0.05)$.

TABLE 4: Means and standard deviations of $V_{\mathrm{m}}(\%)$ for each group.

\begin{tabular}{|c|c|c|c|c|c|c|c|c|}
\hline Mat & C & 5 & & & & DIP-5 & & \\
\hline 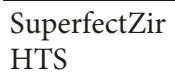 & 4 & .98 & 15.41 & 37.58 & 3.43 & 1.40 & $\mathrm{a}, \mathrm{C}$ & 31. \\
\hline Katana HT & $3.14(0.01)^{\mathrm{a}, \mathrm{A}}$ & $7.89(0.74)^{\mathrm{b}, \mathrm{B}}$ & $11.38(1.22)^{\mathrm{b}, \mathrm{C}}$ & $18.71(1.85)^{\mathrm{a}, \mathrm{D}}$ & $3.06(0.53)^{\mathrm{a}, \mathrm{A}}$ & $7.26(0.15)^{\mathrm{a}, \mathrm{B}}$ & $8.49(0.67)^{\mathrm{b}, \mathrm{C}}$ & $14.64(2.02)^{\mathrm{b}, \mathrm{D}}$ \\
\hline
\end{tabular}

${ }^{*}$ Values marked with the same lowercase letter were not significantly different within a column $(P>0.05)$. Values marked with the same uppercase letter were not significantly different in each group $(P>0.05)$.

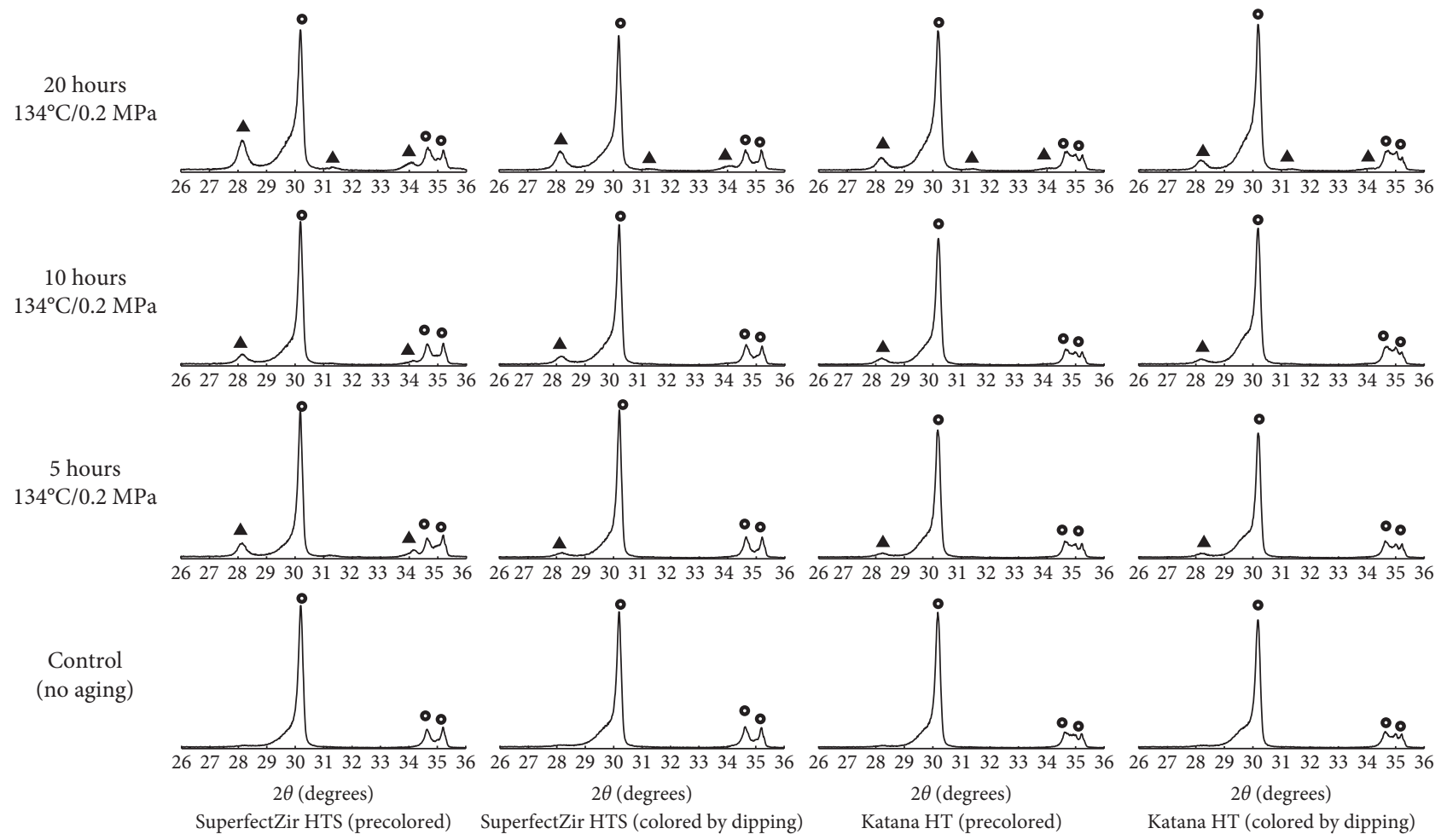

FIGURE 1: XRD patterns of the materials tested ( $\boldsymbol{\Lambda}$, monoclinic phase; $\bullet$, tetragonal phase).

based on the amount of $\mathrm{t} \rightarrow \mathrm{m}$ transformation. However, this correlation was estimated based on the in vivo data obtained from extracted zirconia hip joint heads and might not be applicable to dental zirconia, which is exposed to daily intraoral usage. In one recent publication, accelerated aging $\left(134^{\circ} \mathrm{C}, 0.2 \mathrm{MPa}\right)$ for $5 \mathrm{~h}$ was considered equivalent to in vivo aging for 2 years [26]. Thus, the prolonged aging time used $(20 \mathrm{~h})$ could be considered to simulate 8 years of intraoral aging. However, one should be very careful with such transfers, as the hydrothermal aging does not include any mechanical loading as is present intraorally. Future studies subjecting the Y-TZP materials to drastic environments such as fatigue tests and long periods in the presence of moisture are required to fully comprehend the effect of coloring procedures on the aging behavior of Y-TZP.

Limited information is available regarding the effects of coloring procedures on the aging behavior of Y-TZP. Sen et al. [27] examined the monolithic zirconia subjected to the coloring liquid application and reported that the coloring procedure did not significantly affect biaxial flexural strength. Kaya [28] produced precolored zirconia blocks using different mixtures of raw zirconia powder and $\mathrm{Fe}_{2} \mathrm{O}_{3}$. No negative effects were found on the phase transformation and the mechanical properties (surface microhardness and fracture 


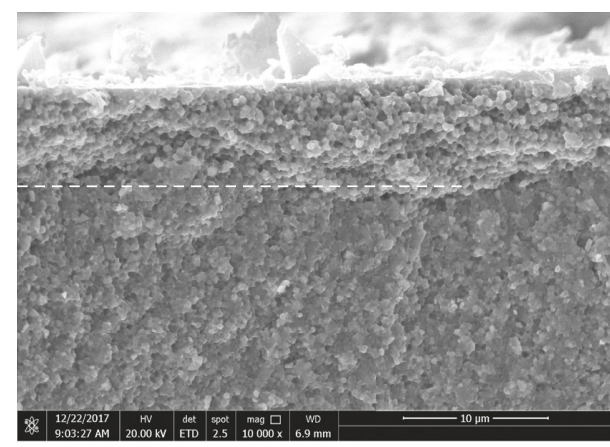

(a)

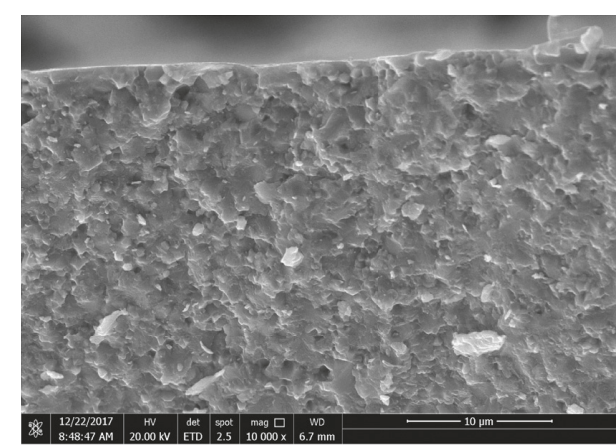

(b)

Figure 2: Fracture surfaces of specimens after aging for $20 \mathrm{~h}$ : (a) SuperfectZir HTS and (b) Katana HT. The region transformed due to the hydrothermal aging is indicated by the dashed lines.

toughness). Shah et al. [20] compared the biaxial flexural and phase transformation of monolithic zirconia colored by immersion in various coloring liquids (cerium acetate and bismuth chloride). The flexural strength decreased, which depended on the concentration of the coloring oxide. Furthermore, there was no detectable amount of monoclinic phase in zirconia after aging at $134^{\circ} \mathrm{C}$ and $0.2 \mathrm{MPa}$ for $10 \mathrm{~h}$. In the literature, an increase in the monoclinic phase has been proposed to lead to higher surface roughness and lower flexural strength $[29,30]$. These deleterious effects may not appear until $V_{\mathrm{m}}$ reaches a critical threshold. However, no consensus has been reached regarding the critical threshold for the surface $V_{\mathrm{m}}$ of Y-TZP. Flinn et al. [31] showed a rapid transformation in the first $50 \mathrm{~h}$ of hydrothermal aging for the monolithic zirconia (Prettau) and slow transformation for other materials (ZirPrime and ZirTough). Some specimens spontaneously fractured after extended periods $(200 \mathrm{~h}$ of hydrothermal aging). Kim et al. [32] investigated the flexural strength of Y-TZP ceramics after various aging treatments, and the results indicated that the threshold of $V_{\mathrm{m}}$, at which point the flexural strength begins to decrease, was $12-54 \%$. Furthermore, $V_{\mathrm{m}}$ of up to $40 \%$ at the surface of Y-TZP did not significantly influence the biaxial flexural strength, which has recently been confirmed by Wille et al. [12]. Although a significant $\mathrm{t} \rightarrow \mathrm{m}$ transformation was observed, aging did not impair the flexural strength of Y-TZP in the present study, which is also consistent with a recently published systematic review stating that there is no decrease in flexural strength up to $50 \%$ of phase transformation at the surface [15]. The $t \rightarrow m$ transformation in Y-TZP originates at the surface and progresses to the subsurface level [33]. Microcracks in the transformed surface layer may act as crack-like flaws and decrease the flexural strength. In the present study, the depth of transformation varied between different materials and only occurred in a superficial layer of the material. This finding is also supported by a previous study [13]. The finding that the flexural strength of the Y-TZP after aging remained unchanged could be attributed to the relatively small transformation depth of the aged materials.

In the present study, the Y-TZP colored by dipping, having a significantly lower $\mathrm{t} \rightarrow \mathrm{m}$ transformation, is considered more resistant to aging than the precolored material.
Limited information is available regarding the coloring compounds in the precolored materials, and the influence of certain metal oxides on the aging behavior cannot be determined. This improved aging resistance can potentially be explained by the ceria in the coloring liquid acting as a sintering aid $[29,30]$. However, this hypothesis must be tested in a future study. It is evident that the 2 Y-TZP differed in the chemical and phase compositions (Table 1 and Figure 1). Katana HT has more ytrria and a larger amount of untransformable cubic phase, which is probably the reason for a lower susceptibility to LTD. Moreover, the coloring procedure had no significant effect on the flexural strength of the tested materials, which is consistent with the previous studies $[4,27]$. According to ISO standard 13356: 2008 , aging should be performed using an autoclave at $134^{\circ} \mathrm{C}$ and $0.2 \mathrm{MPa}$ for $5 \mathrm{~h}$. The zirconia tested should not have more than $25 \% V_{\mathrm{m}}$ after aging [34]. Therefore, the $2 \mathrm{ma}-$ terials fulfilled these criteria and could be considered suitable for biomedical purposes. However, it is important to note that other factors, such as surface treatment, may have a considerable influence on the amount of phase transformation of the zirconia subjected to aging [35].

\section{Conclusion}

Within the limits of this study, the following conclusions can be drawn:

(1) Aging and coloring procedures showed no significant effects on the flexural strength of the tested Y-TZP.

(2) It appears that coloring by dipping may decrease the effect of hydrothermal aging on the susceptibility to phase transformation of the tested Y-TZP.

\section{Data Availability}

The data used to support the findings of this study are available from the corresponding author upon request.

\section{Conflicts of Interest}

The authors declare that there are no conflicts of interest with any institution or funding body. 


\section{Authors' Contributions}

Check Agingu and Neng-wu Jiang contributed equally to this work.

\section{Acknowledgments}

This work was supported by the Program for New Century Excellent Talents in Fujian Province University (Grant no. 2016B033) and the Fundamental Research Funds for the Youth Talent of Fujian Province (Grant no. 2014).

\section{References}

[1] Y. Zhang and J. R. Kelly, "Dental ceramics for restoration and metal veneering," Dental Clinics of North America, vol. 61, no. 4, pp. 797-819, 2017.

[2] K. Harada, A. Shinya, H. Gomi, Y. Hatano, A. Shinya, and A. J. Raigrodski, "Effect of accelerated aging on the fracture toughness of zirconias," Journal of Prosthetic Dentistry, vol. 115 , no. 2 , pp. 215-223, 2016.

[3] D. Manoharan, A. Loganathan, V. Kurapati, and V. J. Nesamony, "Unique sharp photoluminescence of sizecontrolled sonochemically synthesized zirconia nanoparticles," Ultrasonics Sonochemistry, vol. 23, pp. 174-184, 2015.

[4] M. Sedda, A. Vichi, M. Carrabba, A. Capperucci, C. Louca, and M. Ferrari, "Influence of coloring procedure on flexural resistance of zirconia blocks," Journal of Prosthetic Dentistry, vol. 114, no. 1, pp. 98-102, 2015.

[5] N. Djaker, C. Wulfman, M. Sadoun, and M. L. de la Chapelle, "Zirconia dental implants degradation by confocal Raman microspectroscopy: analytical simulation and experiments," Biomedical Optics Express, vol. 4, no. 5, pp. 725-731, 2013.

[6] P. Pandoleon, E. Kontonasaki, N. Kantiranis et al., "Aging of 3Y-TZP dental zirconia and yttrium depletion," Dental Materials, vol. 33, no. 11, pp. e385-e392, 2017.

[7] G. M. De Souza, A. Zykus, R. R. Ghahnavyeh, S. K. Lawrence, and D. F. Bahr, "Effect of accelerated aging on dental zirconiabased materials," Journal of the Mechanical Behavior of Biomedical Materials, vol. 65, pp. 256-263, 2017.

[8] S. Lawson, "Environmental degradation of zirconia ceramics," Journal of the European Ceramic Society, vol. 15, no. 6, pp. 485-502, 1995.

[9] I. Denry and J. R. Kelly, "State of the art of zirconia for dental applications," Dental Materials, vol. 24, no. 3, pp. 299-307, 2008.

[10] J. A. Munoz-Tabares, E. Jimenez-Pique, and M. Anglada, "Subsurface evaluation of hydrothermal degradation of zirconia," Acta Materialia, vol. 59, no. 2, pp. 473-484, 2011.

[11] C. Wulfman, N. Djaker, N. Dupont, D. Ruse, M. Sadoun, and M. L. de la Chapelle, "Raman spectroscopy evaluation of subsurface hydrothermal degradation of zirconia," Journal of the American Ceramic Society, vol. 95, no. 7, pp. 2347-2351, 2012.

[12] S. Wille, P. Zumstrull, V. Kaidas, L. K. Jessen, and M. Kern, "Low temperature degradation of single layers of multilayered zirconia in comparison to conventional unshaded zirconia: phase transformation and flexural strength," Journal of the Mechanical Behavior of Biomedical Materials, vol. 77, pp. 171-175, 2018.

[13] B. D. Flinn, A. J. Raigrodski, L. A. Mancl, R. Toivola, and T. Kuykendall, "Influence of aging on flexural strength of translucent zirconia for monolithic restorations," Journal of Prosthetic Dentistry, vol. 117, no. 2, pp. 303-309, 2017.

[14] J. Chevalier, L. Gremillard, and S. Deville, "Low-temperature degradation of zirconia and implications for biomedical implants," Annual Review of Materials Research, vol. 37, no. 1, pp. 1-32, 2007.

[15] G. Pereira, M. Amaral, P. F. Cesar, M. C. Bottino, C. J. Kleverlaan, and L. F. Valandro, "Effect of lowtemperature aging on the mechanical behavior of ground Y-TZP," Journal of the Mechanical Behavior of Biomedical Materials, vol. 45, pp. 183-192, 2015.

[16] G. K. R. Pereira, S. Fraga, A. F. Montagner, F. Z. M. Soares, C. J. Kleverlaan, and L. F. Valandro, "The effect of grinding on the mechanical behavior of Y-TZP ceramics: a systematic review and meta-analyses," Journal of the Mechanical Behavior of Biomedical Materials, vol. 63, pp. 417-442, 2016.

[17] A. Maerten, P. Zaslansky, C. Mochales et al., "Characterizing the transformation near indents and cracks in clinically used dental yttria-stabilized zirconium oxide constructs," Dental Materials, vol. 29, no. 2, pp. 241-251, 2013.

[18] J. Hjerppe, T. Narhi, K. Froberg, P. K. Vallittu, and L. V. J. Lassila, "Effect of shading the zirconia framework on biaxial strength and surface microhardness," Acta Odontologica Scandinavica, vol. 66, no. 5, pp. 262-267, 2008.

[19] S. Ban, T. Suzuki, K. Yoshihara, K. Sasaki, T. Kawai, and H. Kono, "Effect of coloring on mechanicak properties of dental zirconia," Journal of Medical and Biological Engineering, vol. 34, no. 1, pp. 24-29, 2014.

[20] K. Shah, J. A. Holloway, and I. L. Denry, "Effect of coloring with various metal oxides on the microstructure, color, and flexural strength of 3Y-TZP," Journal of Biomedical Materials Research Part B: Applied Biomaterials, vol. 87, no. 2, pp. 329-337, 2008.

[21] International Organization of Standardization, ISO 6872: 2015, Dentistry-Ceramic Materials, ISO, Geneva, Switzerland, 2015.

[22] R. C. Garvie and P. S. Nicholson, "Phase analysis in zirconia systems," Journal of the American Ceramic Society, vol. 10, no. 6, pp. 1527-1535, 1972.

[23] H. K. Kim and S. H. Kim, "Comparison of the optical properties of pre-colored dental monolithic zirconia ceramics sintered in a conventional furnace versus a microwave oven," Journal of Advanced Prosthodontics, vol. 9, no. 5, pp. 394-401, 2017.

[24] H. Toraya, M. Yoshimura, and S. Somiya, "Calibration curve for quantitative analysis of the monoclinic tetragonal $\mathrm{ZrO}_{2}$ system by X-rays diffraction," Journal of the American Ceramic Society, vol. 67, no. 6, pp. 119-121, 1984.

[25] J. Chevalier, J. M. Drouin, and B. Cales, "Low temperature ageing behavior of zirconia hip joint heads," Bioceramics, vol. 10, pp. 135-137, 1997.

[26] M. Cattani-Lorente, S. Durual, M. Amez-Droz, H. W. Anselm Wiskott, and S. S. Scherrer, "Hydrothermal degradation of a 3Y-TZP translucent dental ceramic: a comparison of numerical predictions with experimental data after 2 years of aging," Dental Materials, vol. 32, no. 3, pp. 394-402, 2016.

[27] N. Sen, I. B. Sermet, and S. Cinar, "Effect of coloring and sintering on the translucency and biaxial strength of monolithic zirconia," Journal of Prosthetic Dentistry, vol. 119, no. 2, 2017.

[28] G. Kaya, "Production and characterization of self-colored dental zirconia blocks," Ceramic International, vol. 39, no. 1, pp. 511-517, 2013.

[29] M. T. Hernandez, J. R. Jurado, P. Duran, and J. L. G. Fierro, "Subeutectoid degradation of yttria-stabilized tetragonal 
zirconia polycrystal and ceria-doped yttria-stabilized tetragonal zirconia polycrystals ceramics," Journal of the American Ceramic Society, vol. 74, no. 6, pp. 1254-1258, 1991.

[30] J. G. Duh and M. Y. Lee, "Fabrication and sinterability in $\mathrm{Y}_{2} \mathrm{O}_{3}-\mathrm{CeO}_{2}-\mathrm{ZrO}_{2}$," Journal of Materials Science, vol. 24, no. 12, pp. 4467-4474, 1989.

[31] B. D. Flinn, A. J. Raigrodski, A. Singh, and L. A. Mancl, "Effect of hydrothermal degradation on three types of zirconias for dental application," Journal of Prosthetic Dentistry, vol. 112, no. 6, pp. 1377-1384, 2014.

[32] H. T. Kim, J. S. Han, J. H. Yang, J. B. Lee, and S. H. Kim, “The effect of low temperature aging on the mechanical property \& phase stability of Y-TZP ceramics," Journal of Advanced Prosthodontics, vol. 1, no. 3, pp. 113-117, 2009.

[33] T. J. Lucas, N. C. Lawson, G. M. Janowski, and J. O. Burgess, "Phase transformation of dental zirconia following artificial aging," Journal of Biomedical Materials Research Part B: Applied Biomaterials, vol. 103, no. 7, pp. 1519-1523, 2015.

[34] V. Lughi and V. Sergo, "Low temperature degradation -agingof zirconia: a critical review of the relevant aspects in dentistry," Dental Materials, vol. 26, no. 8, pp. 807-820, 2010.

[35] M. Inokoshi, K. Vanmeensel, F. Zhang et al., "Aging resistance of surface-treated dental zirconia," Dental Materials, vol. 31, no. 2, pp. 182-194, 2015. 

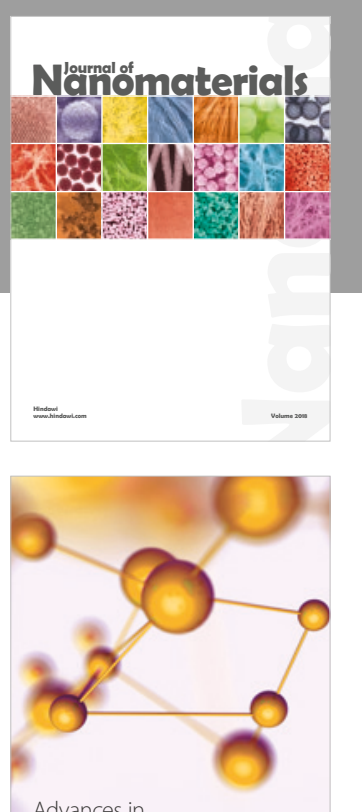

Physical Chemistry
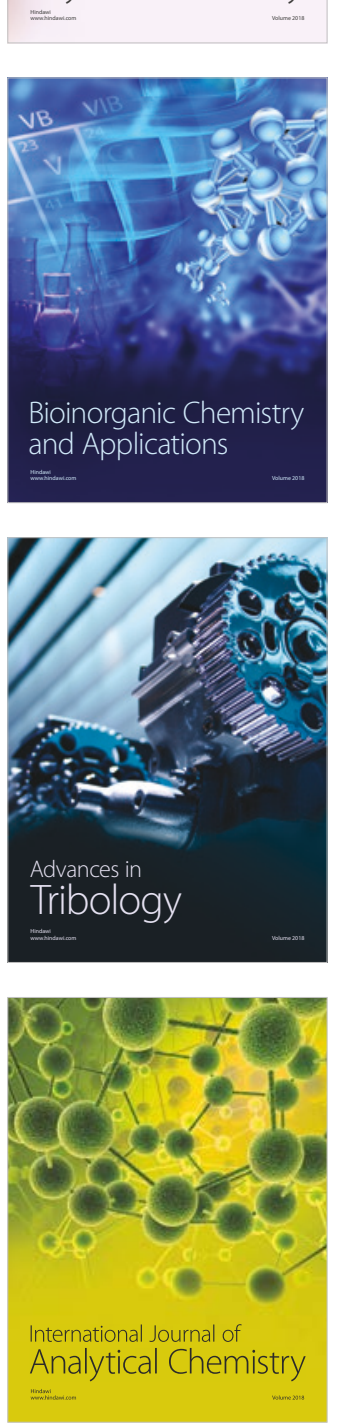

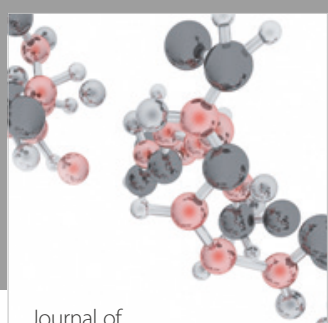

Analytical Methods

in Chemistry

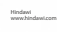

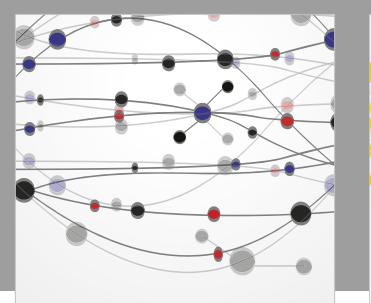

The Scientific World Journal

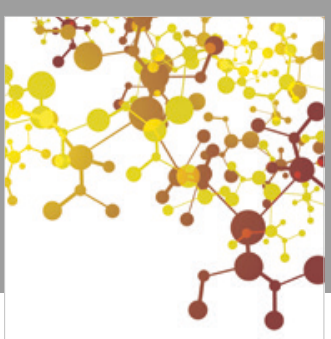

Journal of

Applied Chemistry
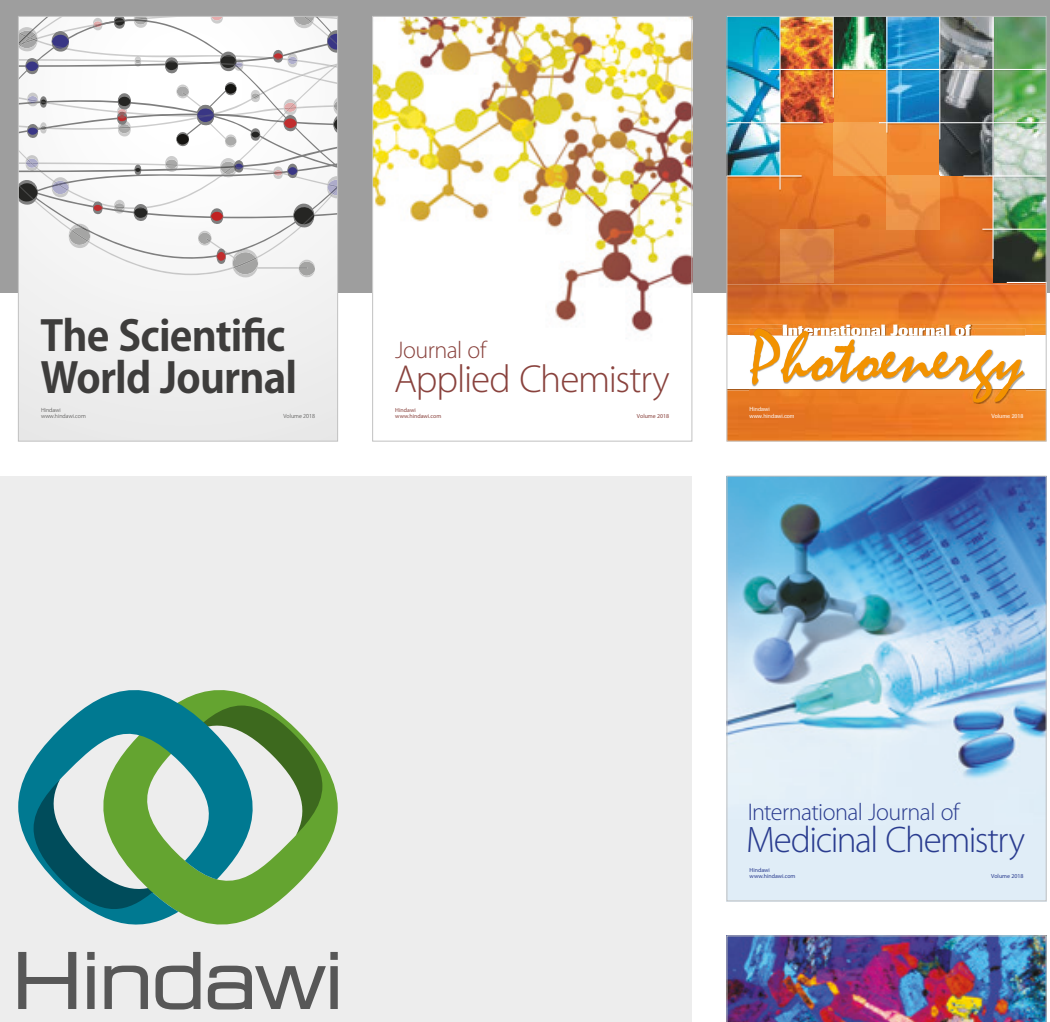

Submit your manuscripts at

www.hindawi.com
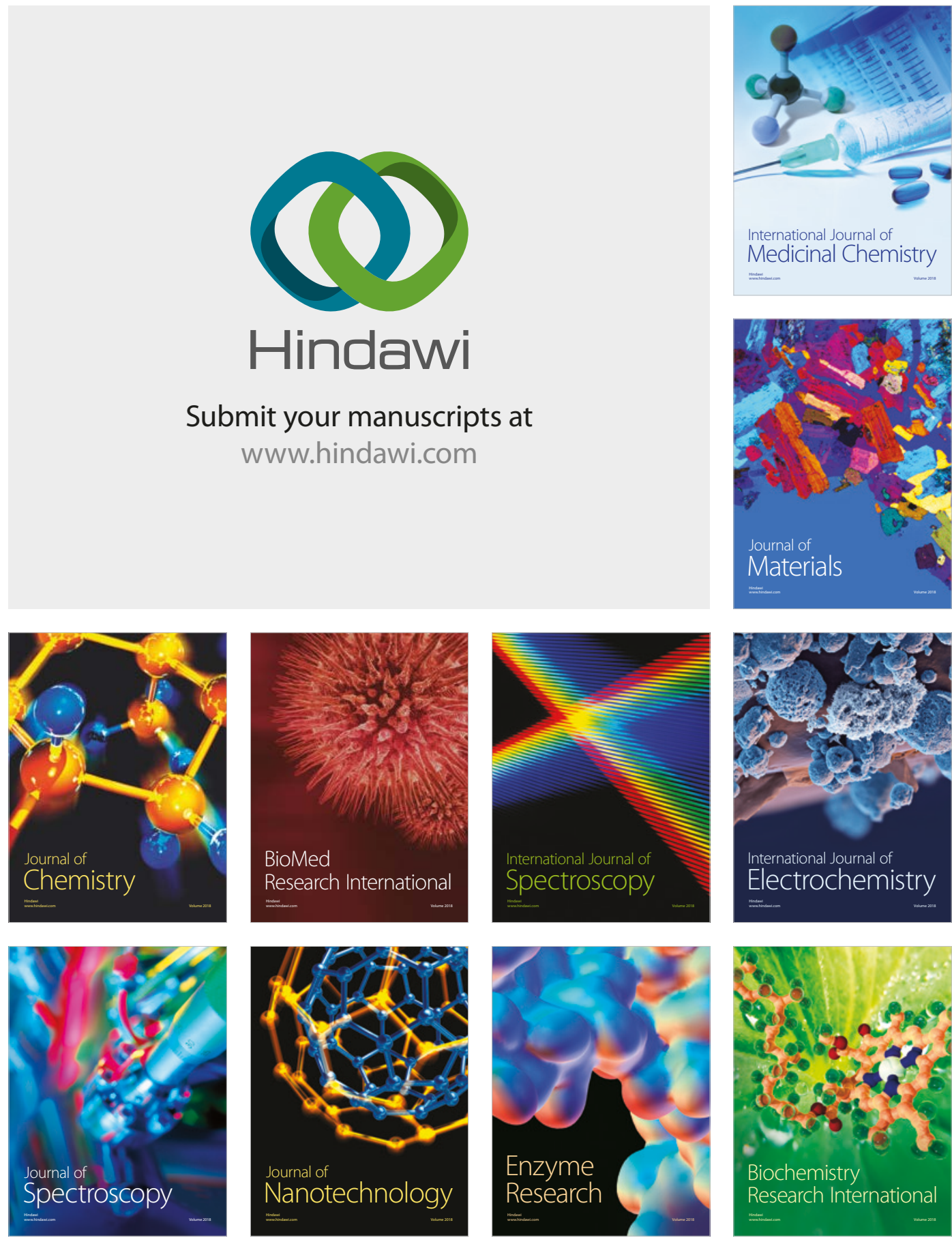
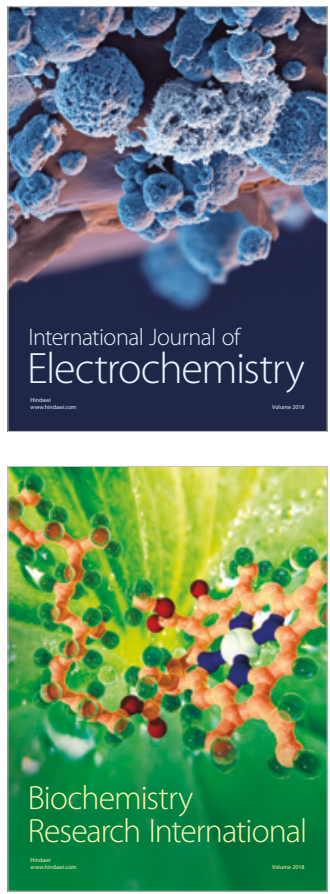